\title{
ANALYSIS OF SOLAR COOKER WITH THERMAL STORAGE FOR REMOTE HILLY AREAS: DETERMINATION OF HEATING AND COOLING CHARACTERISTIC TIME
}

\author{
Geetanjali Raghav* \\ University of Petroleum and Energy Studies, Dehradun, India, graghav@ddn.upes.ac.in \\ Pankaj Kumar Sharma \\ University of Petroleum and Energy Studies, Dehradun, India, Pankjpme@ddn.upes.ac.in
}

\author{
Suresh Kumar
}

Shri Vishwakarma Skill University, India, kumar@svsu.ac.in

Rajesh Maithani

University of Petroleum and Energy Studies, Dehradun, India, rmaithani@ddn.upes.ac.in

\author{
Alexis lung \\ "ENSEM" Université de Lorraine, Vandœuvre-lès-Nancy, France, alexis.iung6@etu.univ-lorraine.fr \\ Quentin Mercier \\ "ENSEM" Université de Lorraine, Vandœuvre-lès-Nancy, France, 21quentin07@gmail.com
}

Article history: Received 5 July 2021, Received in revised form 20 July, Accepted 21 July 2021, Available online 2 August 2021

\begin{abstract}
Solar cooking finds a major application in rural areas of Uttarakhand, India, yet its utilization is still limited due to certain limitation such as intermittent nature of solar radiations. This drawback limits solar cooker in becoming a viable alternate solution of LPG and other pollution causing resources such as wood. In order to cater this problem a numerical analysis of box type solar cooker with storage is carried out. The energy stored in the storage material will keep the cooker warm up to the time when food is consumed. Charging and discharging time analysis is performed in with an aim to understand the effect of storage on solar cooker. Heating and cooling characteristic time are being evaluated and analysed with storage. Thermal performance of box type solar cooker is measured in terms of figures of merit according to BIS standards. The effect of storage has also been analysed in terms of charging and discharging time and first figure of merit of box type solar cooker.it has been observed that during discharging the heat is stored for more duration as compared to the charging time as discharge time is approx. 4-5 hours while charging time for the same amount of insolation is around 3-4 hours.
\end{abstract}

\section{Keywords}

solar energy, solar cooker, thermal storage, thermal performance

\section{Introduction}

One of the most energy-consuming sectors is cooking. In cooking the main energy used is kerosene, liquefied petroleum gases (LPG), biogas or wood. However, this energy damages the environment with pollution or deforestation and cause 1.6 million deaths per year (World health organization]. A lot of literature reported in the different aspects of performance analysis of solar cooker reveals that the thermal performance testing is one of the most prominent aspect of box type solar cooker.

Nevertheless, there exists an alternative with the sun. In several countries, there is an abundant solar radiation with daily solar energy in the range of $5-7 \mathrm{kWh} / \mathrm{m}^{2}$ and number of clear sunny days per year. The advantages are clean energy, non-pollutant, no emissions, and low running costs [1].

The solar cooker is also the ideal candidate to solve this problem and there are different types of solar cookers available for cooking.

A lot of research was focused on improving their efficiencies of various types of solar cookers such as concentrating type, parabolic, panel solar cookers, cookers with variation in shapes or geometry as square and rectangular and cookers with storage.

The first thermal performance analysis was led by Volunteers in Technical Assistance (VITA) [2], the evaluation was on different measures, for example, cooking execution, strength, cost. 
Various parametric performance analysis of solar cooker can be fetched from literature review [3-5]. The literatures reviewed are helpful during the design and development of solar cookers according to the demographic conditions.

Different techno monetary psychological factors scaled on 100 pointer scale were evaluated by an examination announced by Bowman and Blatt [6], transient model for a single glazed box type solar cooker was proposed by Garg et al. [7] predicted the temperature profile for various elements of the cooker. Certain improvements were added by Vaishya et al. [8] in a box type solar cooker.

A concentrating-type cooker is composed of multifaceted mirrors, Fresnel lens, and parabolic or spherical collectors to reach higher temperatures. Generally, this cooker can be designed with one or two axis-tracking systems to follow the course of the sun to determine the optimal angle of reflector which varies at every hour, that's why this oven can be equipped of point tracking (MPPT) techniques like a solar panel $[9,10]$.

The principle of non-focusing type cookers is based on a heat transfer fluid that carries thermal energy until an oven. Simply, the fluid is heated by the solar radiation then the fluid heats the oven. This is the same principle as solar heating. This category is more useful for indoor cooking application nevertheless it is more expensive to produce [10].

A box-type solar cooker is composed of an insulated box with a transparent glass cover (generally double glazing). The absorber part is usually made up of material with a high conductivity and painted black to increase the sunlight absorption and reduce reflection. The temperature of a solar box cooker can be raised to around $100^{\circ} \mathrm{C}$ but like each component of the box has a significant influence on cooking power, the temperature can be higher than $100^{\circ} \mathrm{C}[1,10]$.

A different sub-category of cooker which can equip the three previously cooker are the direct-type solar cooker receiving direct solar radiation. The indirect cooker uses a heat transfer fluid to transfer the energy from the collector to the cooking unit. Classic cookers can be equipped with one or two-axis-tracking systems to follow the sun [10].

Geddam et al. [11] worked on experimental analysis and obtained F2 using a test procedure to determine these parameters under different load conditions of water. The procedure is used to generate heating characteristic curves of the solar cooker. Manuel et al. [12] proposed a revision and formulated the revision in the existing standards.

Even if the solar cooker is used to cook food, its biggest problem is if there is insufficient or no sunshine, the cooker does not work that is why storage can be added to the cooker. This addition of thermal storage will help in keeping the solar cooker hot for an extended amount of time, after the sunset. This work focusses on the study of a mathematical model to find the temperature of the storage and determine the characteristic time of heating and cooling of this storage integrated with box type solar cooker. The performance has been evaluated considering the solar cooker with and without storage.

\section{Methods}

Theoretical model of the solar cooker without storage

In his article [6], Mullick determines the balance energy of a box-type solar cooker:

$$
\eta_{0} H_{S}=U_{L}\left(T_{p s}-T_{a s}\right)
$$

where:

- $\eta_{0}$ is the optical efficiency calculated with the absorption of each wall.

- $H_{S}$ the insulation on a horizontal surface

- $\mathrm{U}_{\mathrm{L}}$ the heat loss factor, a method to calculate this factor will be explained in the next part.

- $T_{p s}$ the plate stagnation temperature

- $T_{a s}$ the ambient stagnation temperature

He determines the first figure of merits:

$$
F_{1}=\frac{T_{p s}-T_{a s}}{H_{S}}=\frac{\eta_{0}}{U_{L}}
$$

It is obtained by keeping the solar cooker without vessels in the sunshine in the morning between 10 am and 2 pm. 
This parameter allows to determine the performance of an empty solar cooker which is considered good when:

$$
0.12<F_{1}<0.16
$$

Mullick describes another parameter: the second figure of merits $F_{2}$ which determines the performance of a full solar cooker and depends on the load and the number of the pots inside the cooker [5].

$F_{2}$ is independent of climatic variables and is dimensionless. it is considered good when:

$$
0.254<F_{2}<0.490
$$

Theoretical model of the solar cooker

The MNRE Model of box type solar cooker is considered for analysis.

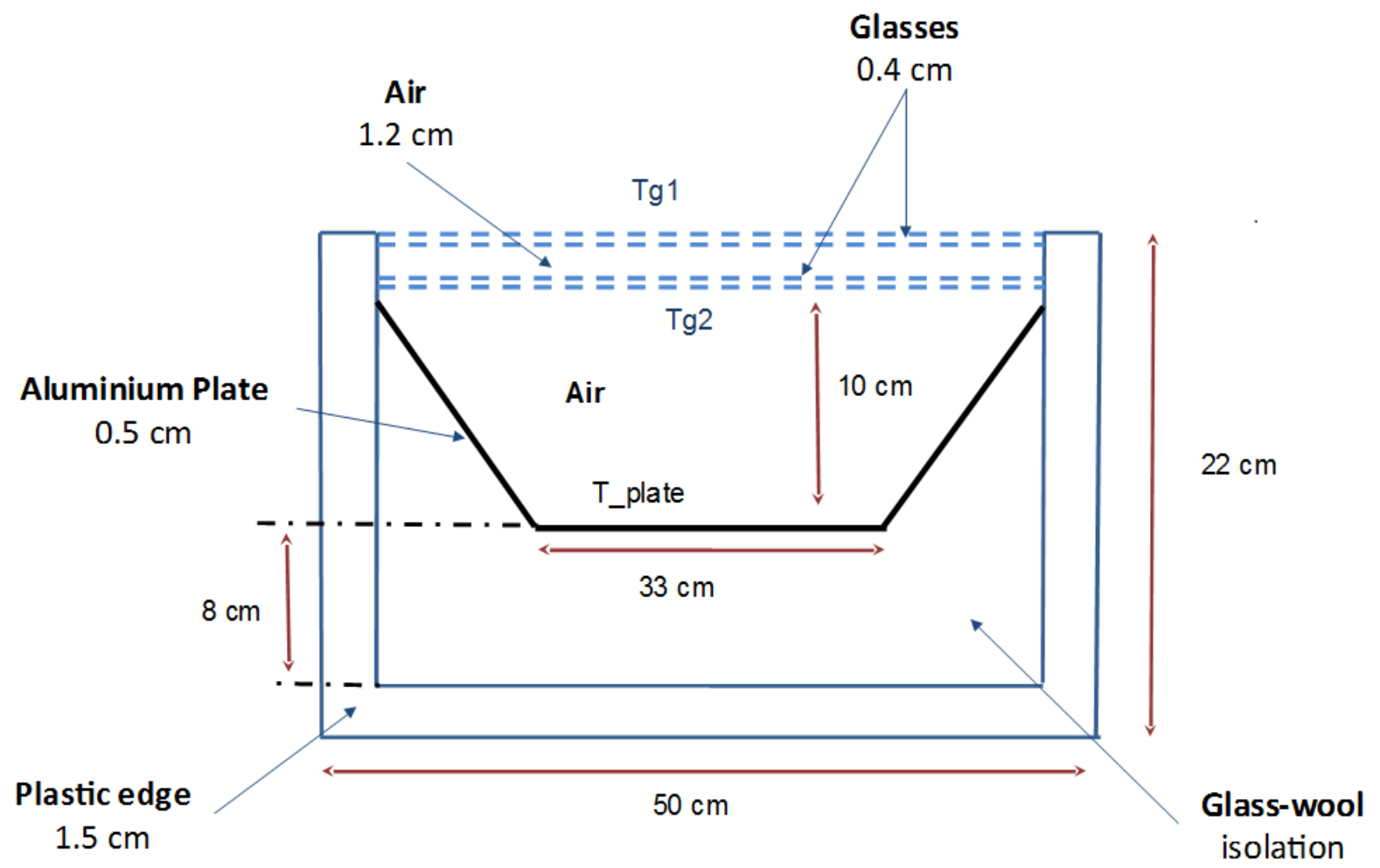

Fig. 1. Schematic of box type Solar cooker

The ambient temperature is assumed to be $T_{a}=35^{\circ} \mathrm{C}$.

Since convection coefficients are necessary to evaluate flows between walls, these coefficients are calculated by using various correlation.

The following expressions are calculated at the interface temperature $T_{m}$.

First, the Rayleigh number is needed:

$$
R a=\frac{g \beta\left(T_{p}-T_{\infty}\right) L_{C}^{3}}{v^{2}} \operatorname{Pr}
$$

where :

- $\mathrm{g}$ is the gravitational acceleration

- $\beta=\frac{1}{T_{m}}$, here the air is considered as a perfect gas 
- $\quad L_{C}$ the characteristic length

- $\quad$ the air Prandtl number $\operatorname{Pr}=0.9257 T_{m}^{-0.0457}$

- the air dynamic viscosity $v=8.03 \times 10^{-10} T_{m}^{1.7354}$

The Nusselt number for a rectangular closed cell should be calculated with:

(4)

$$
N u=1+1.44\left(1-\frac{170}{R a}\right)+\left[\left(\frac{R a}{5830}\right)^{\frac{1}{3}}-1\right]
$$

Then, the convective coefficient is equal to :

(5)

$$
h=\frac{N u \lambda}{L_{C}}
$$

with:

- $\quad L_{C}$ the characteristic length

- $\lambda$ the air conductivity $\lambda=0.0002045 T_{m}^{0.85}$

Expressions of $\lambda, v$ and $\operatorname{Pr}$ come from Duffie [2].

However, in natural convection, the wall temperatures are needed: $T_{g 1}, T_{g 2}$, and $T_{p}$.

Determination of glasses and plate temperature

The electrical analogy of Duffie is followed [2]:

with:

- the external radiation:

(6)

$$
h_{r, a-g 1}=\frac{\sigma \varepsilon_{g 1}\left(T_{g 1}+T_{s k y}\right)\left(T_{g 1}^{2}+T_{s k y}^{2}\right)\left(T_{g 1}-T_{s k y}\right)}{\left(T_{g 1}-T_{a}\right)}, T_{s k y} \approx T_{a}
$$

- the external convection:

(7)

$$
h_{\text {wind }}=5.7+3.8 v
$$

$v$ is the velocity of the air

- the radiation between the two glasses :

(8)

$$
h_{r, g 1-g 2}=\frac{\sigma\left(T_{g 1}+T_{g 2}\right)\left(T_{g 1}^{2}+T_{g 2}^{2}\right)}{\frac{1}{\varepsilon_{g 1}}+\frac{1}{\varepsilon_{g 2}}-1}
$$

- the convection between the two glasses is determined with the previous correlation, $\mathrm{h}_{\mathrm{c}, \mathrm{g} 1-\mathrm{g} 2}$

- the radiation between the second glass and the plate:

(9)

$$
h_{r, g 2-p}=\frac{\sigma\left(T_{g 2}+T_{p}\right)\left(T_{g 2}^{2}+T_{p}^{2}\right)}{\frac{1}{\varepsilon_{g 2}}+\frac{1}{\varepsilon_{p}}-1}
$$

- the convection between the second glass and the plate is determined with the previous correlation, $h_{c, g 2-p}$

The thermal resistance is:

$$
R_{1}=\frac{1}{h_{\text {wind }}+h_{r, a-g 1}}
$$


(11)

$$
\begin{array}{r}
R_{2}=\frac{1}{h_{c, g 1-g 2}+h_{r, g 1-g 2}} \\
R_{3}=\frac{1}{h_{c, g 2-p}+h_{r, g 2-p}}
\end{array}
$$

the following resistance are for the conduction :

$$
R_{i}=\frac{e_{i}}{\lambda_{i}}
$$

Now, the top loss heat coefficient can be calculated:

$$
U_{t}=\frac{1}{R_{1}+R_{2}+R_{3}}
$$

The side and bottom loss heat coefficient are calculated with the sum of the conduction resistance:

$$
U_{s}=\frac{1}{R_{\text {cond }, S}} \text { and } U_{b}=\frac{1}{R_{\text {cond }, b}}
$$

The total heat loss is:

$$
U_{L}=U_{t}+U_{s}+U_{b}
$$

Finally, temperatures are determined with:

$$
T_{j}=T_{i}+\frac{U_{t}\left(T_{p}-T_{a}\right)}{h_{c, i-j}+h_{r, i-j}}
$$

The plate temperature will be calculated with the Mullick [13].

Theoretical model of the solar cooker with storage.

Different types of storage.

The storage unit in a solar cooker is also an important issue. Indeed to overcome the alternative aspect of the sun it could be interesting to add a storage unit at the solar cooker. The storage unit's goal is to store energy during a time that the user doesn't need it and redistribute it when the user will. It is a way to delay the time of energy availability and consumption. There are two main thermal energy storages: sensible heat and latent heat.

The sensible heat storage consists of warm-up a material (fluid or solid). The range of temperature during this operation does not include a phase change of the material. The heat stored in this material is given by equation $Q=m C_{P} \Delta T$.

On another hand, Latent heat storage use Phase Change Materials called PCMs. This storage method uses the chemical properties of PCMs. Indeed the heat could be stored is given by with the Latent heat of phase change. With this storage way, a large energy quantity is stored at the phase change temperature because $\Delta H_{12}$ is significantly bigger (around $10^{6} \mathrm{~J} . \mathrm{kg}^{-1}$ for vaporization enthalpy of water) than specific heat $\left(10^{3} \mathrm{Jkg}^{-1} \mathrm{~K}^{-1}\right)$. It is said that Latent heat storage has a capacity between 5 to 14 times more than Sensible heat storage, the equation is given by

$$
Q=m C_{p_{\text {phase } 1}} \Delta T+m \Delta H_{12}+m C_{p_{\text {phase } 2}} \Delta T
$$


However, Latent heat storage begets a large volume variation in the opposite of sensible heat storage. Moreover, a sensible heat storage unit is easier to implement on a cooker. The storage material must be chosen according to some criteria based on mechanical or thermal properties, availability, recyclability, price, etc. Some properties in the sensible heat storage material are important as thermal conductivity, density, and specific heat and diffusivity. Sensible heat storage materials can be classified into 4 groups [4].

Sensible heat storage is chosen for the rest of the study. A magnesia brick with a thickness of $50 \mathrm{~cm}$ is added in the initial cooker:

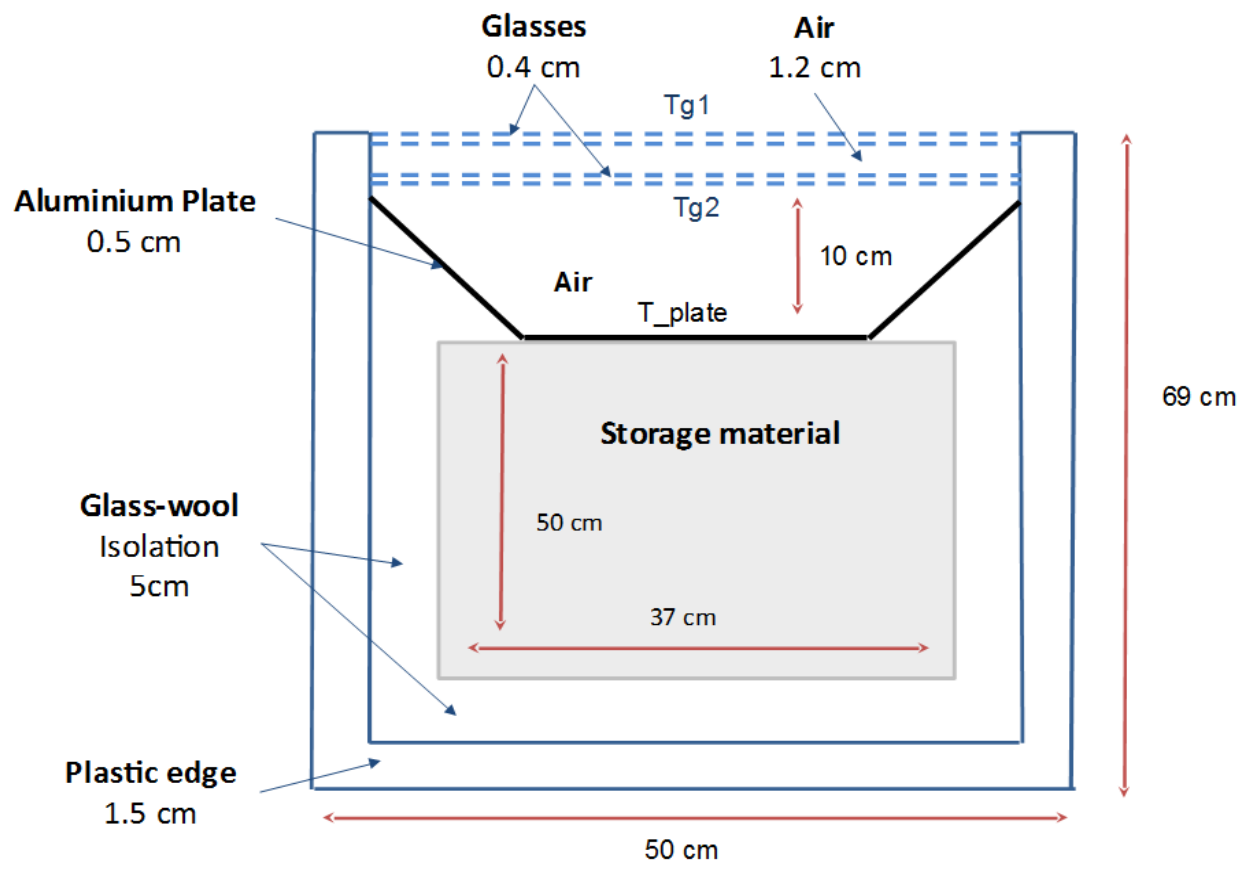

Fig. 2. Schematic of cooker with storage.

The goal of this part is to determine the characteristic time of heating and cooling of the brick. To simplify the problem, the magnesia brick will begin to heat when the plate is at its final temperature. The storage temperature is supposed constant on the surface and depends only on the thickness.

Only conduction is considered in the problem, the heat equation is also:

$$
\frac{\partial T_{S}}{\partial t}-a \frac{\partial^{2} T_{S}}{\partial z^{2}}=\frac{p}{\rho C}
$$

with the source term $p=\alpha_{g 1} \times \alpha_{g 2} \times \alpha_{p} \times \alpha_{s} \times S_{s} \times H_{s}$.

To solve this equation, the finite difference method is used and only the explicit method will be used [7]. After the discretization, a new system is obtained:

$$
B T^{n+1}=A T^{n}+k F
$$

With:

$$
\left\{\begin{array}{c}
A=\mathbb{I}+\frac{\alpha k}{h^{2}} \\
B=\mathbb{I}
\end{array}\right.
$$


And the rigidity matrix:

[22]

$$
K=\left(\begin{array}{ccccccc}
-2 & 1 & 0 & 0 & 0 & \cdots & 0 \\
1 & -2 & 1 & 0 & 0 & \cdots & 0 \\
0 & 1 & -2 & 1 & 0 & \cdots & 0 \\
& & & & & & \\
0 & \cdots & \cdots & 0 & \ddots & \ddots & 1 \\
0 & \cdots & \cdots & \cdots & 0 & 1 & -2
\end{array}\right)
$$

$k$ is the time step and $h$ is the space step. For the explicit method, $a \frac{k}{h^{2}}<\frac{1}{2}$, else the problem differs. Now, the following vector can be built:

[23]

$$
T^{n+1}=\left(B^{-1} A\right)^{n} T_{0}+k B^{-1} \sum_{p=0}^{n-1}\left(B^{-1} A\right)^{p} F
$$

The size of this vector is $\frac{L}{h}$ and the power $\mathrm{n}$ corresponds with the variation of the temperature about the thickness at a giving time. The following matrix will be built:

[24]

$$
\begin{aligned}
& t=1 s \quad t=2 s \quad \cdots \quad t=n s
\end{aligned}
$$

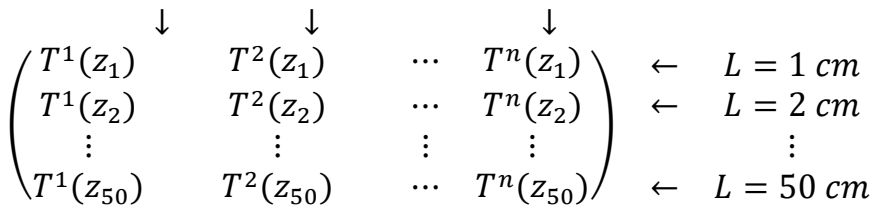

For the charge, the typical solution is:

$$
T_{c h}^{n+1}=T_{0}-\left(B^{-1} A\right)^{n}\left(T_{0}-T_{a}\right)+k B^{-1} \sum_{p=0}^{n-1}\left(B^{-1} A\right)^{p} F
$$

with:

- $T_{0}$ is the stagnation temperature of the plate.

- $T_{a}$ is the ambient temperature.

For the discharge, the source terms disappear, and the heat equation becomes:

$$
\frac{\partial T_{S}}{\partial t}-a \frac{\partial^{2} T_{S}}{\partial z^{2}}=0
$$

The type of solution is:

$$
T_{\text {dis }}^{n+1}=T_{a}-\left(B^{-1} A\right)^{n}\left(T_{a}-T_{0}\right)
$$

The evolution of temperature can be plotted at a given length: For the cooling of the walls, the system becomes: 
[28]

$$
\left\{\begin{array}{c}
\frac{d T_{g 1}}{d t}=\frac{T_{g 1}(t)}{\tau_{g 1}}-\frac{T_{a}}{\tau_{g 1}} \\
\frac{d T_{g 2}}{d t}=-\frac{T_{g 1}(t)}{\tau_{g 2}}+\frac{T_{g 2}(t)}{\tau_{g 2}} \\
\frac{d T_{p}}{d t}=-\frac{T_{g 2}(t)}{\tau_{p}}+\frac{T_{p}(t)}{\tau_{p}}
\end{array}\right.
$$

The characteristic times don't change with the cooling.

\section{Results and discussion}

The determination of heating and cooling characteristic time of a solar cooker is carried out numerically and the results are discussed for the box type solar cooker with and without storage.

\section{Solar cooker without storage}

The calculation for the analysis is initiated by random selection of temperatures $T_{g 1}, T_{g 2}$, and $T_{p}$. Another plate temperature is defined by $T_{p n}$, and this value will be calculated in the loop. In the input data, this value must be different from $T_{p}$. This algorithm also calculates $T_{g 1}, T_{g 2}, T_{p}$, the convective and radiative coefficient of each wall and the heat loss coefficient. The program is feasible for different values of insulation and external air velocity, and the results obtained are summed in the following table 1.

Table 1. Heat loss analysis of a box type solar cooker without storage

\begin{tabular}{|l|l|l|l|l|l|l|l|l|l|l|l|}
\hline $\begin{array}{c}H_{S} \\
\left(W / m^{2}\right)\end{array}$ & $\begin{array}{l}\mathrm{v}(\mathrm{m} / \\
s)\end{array}$ & $T_{g 1}$ & $T_{g 2}$ & $T_{p}$ & $h_{\text {wind }}$ & $h_{r, a-g 1}$ & $h_{c, g 1-g 2}$ & $h_{r, g 1-g 2}$ & $h_{c, g 2-p}$ & $h_{r, g 2-p}$ & $U_{L}$ \\
\hline \multirow{4}{*}{400} & 1 & 44.6 & 75.2 & 100.0 & 9.50 & 19.87 & 2.70 & 6.52 & 2.47 & 8.88 & 4.50 \\
\cline { 2 - 12 } & 2 & 43.5 & 74.3 & 99.2 & 13.30 & 19.79 & 2.72 & 6.46 & 2.48 & 8.82 & 4.56 \\
\cline { 2 - 12 } & 3 & 42.7 & 73.6 & 98.6 & 17.10 & 19.73 & 2.73 & 6.42 & 2.48 & 8.78 & 4.61 \\
\hline \multirow{3}{*}{600} & 1 & 49.3 & 91.0 & 123.7 & 9.50 & 20.27 & 2.97 & 7.28 & 2.48 & 10.56 & 4.98 \\
\cline { 2 - 11 } & 2 & 47.8 & 89.7 & 122.6 & 13.30 & 20.15 & 2.98 & 7.18 & 2.50 & 10.46 & 5.04 \\
\cline { 2 - 11 } & 3 & 46.5 & 88.7 & 121.8 & 17.10 & 20.10 & 3.00 & 7.11 & 2.51 & 10.39 & 5.08 \\
\hline \multirow{3}{*}{800} & 1 & 53.9 & 105.3 & 144.3 & 9.50 & 20.66 & 3.12 & 7.99 & 2.49 & 12.18 & 5.39 \\
\cline { 2 - 11 } & 2 & 51.9 & 103.8 & 143.0 & 13.30 & 20.50 & 3.13 & 7.86 & 2.51 & 12.04 & 5.45 \\
\cline { 2 - 10 } & 3 & 50.2 & 102.5 & 142.0 & 17.10 & 20.36 & 3.16 & 7.76 & 2.52 & 11.94 & 5.50 \\
\hline
\end{tabular}

The data obtained reveals that the temperature of the first glass is a significantly affected by the air velocity. Indeed, this temperature variation is due to the high intensity of forced convection which is cooling the glass surface. However, this convection does not affect the temperature inside the cooker as the velocity changes. It is seen from the table that the wall temperatures rise with increase in the insulation and simultaneously the heat loss coefficient also raises.

Further, the first figure of merits can be calculated. For our system, the magnitude of the optical efficiency calculated is $\eta_{0}=\alpha_{g 1} \times \alpha_{g 2} \times \alpha_{p}=0.736$

The values $F 1$ obtained have been plotted across the plate temperature as shown in Fig. 3: 


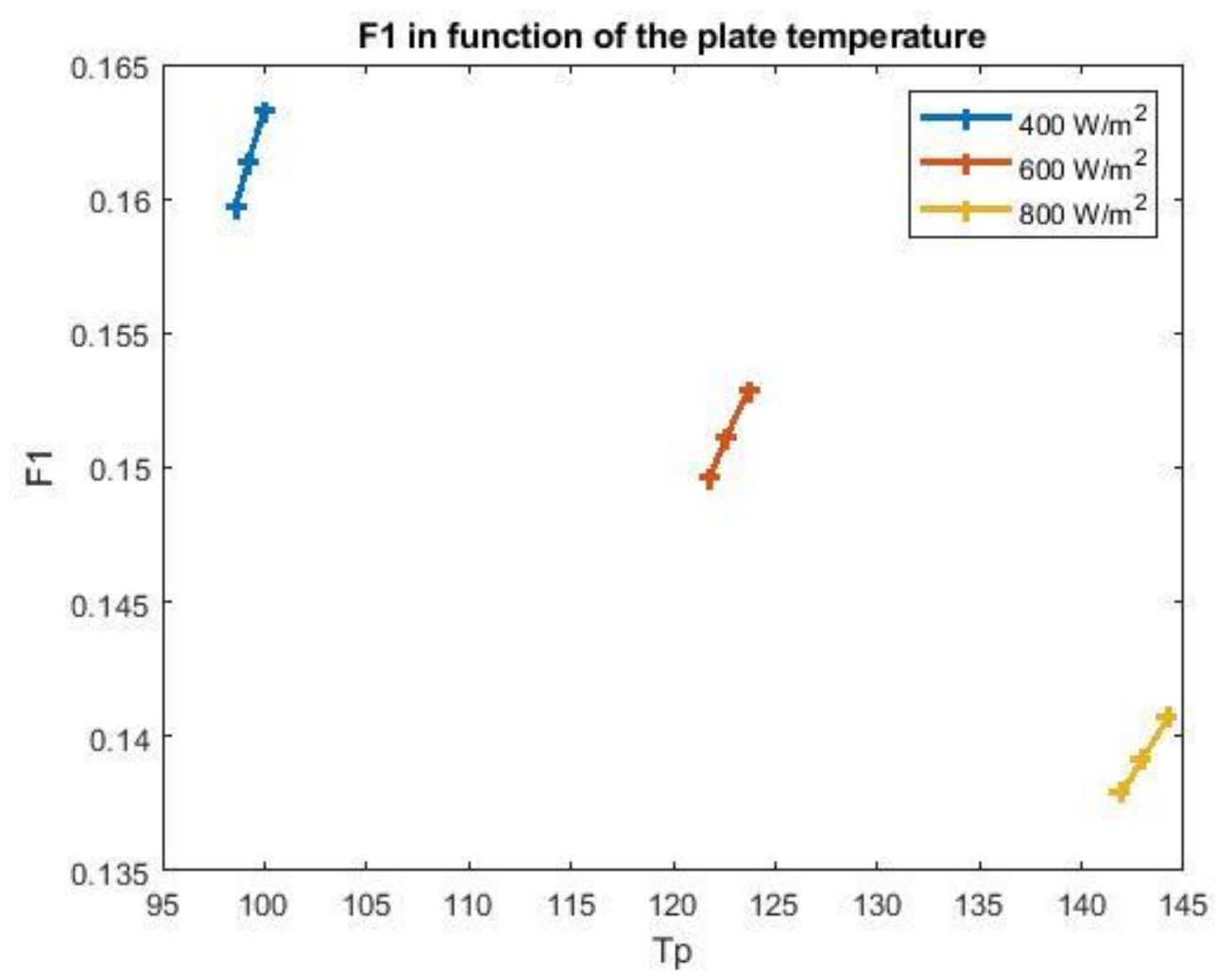

Fig. 3. Variation of $F_{1}$ first figure of merit with plate temperature of solar cooker without storage

It is seen in the figure that the values of the first figure of merit are obtained in the range of $0.1379<F_{1}<$ 0.1633 . Thus the present models selected are acceptable in terms of first figure of merit (F1). It is observed from the figure that an increase in the insulation magnitude lowers the value of first figure of merits. Whereas the higher value of insolation leads to higher plate temperature. It can be explained by the fact that as the temperature of the plate raises with insulation, there is an increase in the heat losses. As the convection current grows with the elevated wall temperatures, reduction in the thermal resistance is seen that leads to heat loss coefficient intensification.

\section{Characteristic time of each element}

The exchanges coefficients for a solar cooker have been calculated in the previous part with a permanent defined approach. Thus a transitory approach is described here. To simplify the heat equation, a calculation of the Biot number is made, with each wall having magnitude of $B i \ll 1$, here the temperature inside each wall is considered to be isotherm. The energy balance equation becomes [2]:

$$
\rho C V \frac{d T_{g}}{d t}=Q_{\text {exchange }}(t)+Q_{\text {source }}(t)
$$

Finally, the following system is obtained:

[30]

$$
\left\{\begin{array}{c}
\frac{d T_{g 1}}{d t}=-\frac{T_{g 1}(t)}{\tau_{g 1}}+\frac{T_{a}}{\tau_{g 1}}+\frac{\alpha_{g 1} H_{s}}{\left(h_{w i n d}+h_{r, a-g 1}\right) \tau_{g 1}} \\
\frac{d T_{g 2}}{d t}=\frac{T_{g 1}(t)}{\tau_{g 2}}-\frac{T_{g 2}(t)}{\tau_{g 2}}+\frac{\alpha_{g 1} \alpha_{g 2} H_{s}}{\left(h_{c, g 1-g 2}+h_{r, g 1-g 2}\right) \tau_{g 2}} \\
\frac{d T_{g p}}{d t}=\frac{T_{g 2}(t)}{\tau_{p}}-\frac{T_{p}(t)}{\tau_{p}}+\frac{\alpha_{g 1} \alpha_{g 2} \alpha_{p} H_{s}}{\left(h_{c, g 2-p}+h_{r, g 2-p}\right) \tau_{p}}
\end{array}\right.
$$


With the characteristic time:

$$
\left\{\begin{array}{c}
\tau_{g 1}=\frac{\rho_{g} C_{g} V_{g}}{S_{g}\left(h_{\text {wind }}+h_{r, a-g 1}\right)} \\
\tau_{g 2}=\frac{\rho_{g} C_{g} V_{g}}{S_{g}\left(h_{c, g 1-g 2}+h_{r, g 1-g 2}\right)} \\
\tau_{g 2}=\frac{\rho_{p} C_{p} V_{p}}{S_{p}\left(h_{c, g 2-p}+h_{r, g 2-p}\right)}
\end{array}\right.
$$

The results obtained for the characteristic time are summed up in Table 2, and the time unit selected is in seconds.

Table 2. Parametric analysis for different insolation conditions

\begin{tabular}{|l|l|l|l|l|}
\hline \multirow{2}{*}{$H_{s}\left(\mathrm{~W} / \mathrm{m}^{2}\right)$} & $\mathrm{v}(\mathrm{m} / \mathrm{s})$ & $\tau_{g 1}(\mathrm{~s})$ & $\tau_{\mathrm{g} 2}(\mathrm{~s})$ & $\tau_{p}(\mathrm{~s})$ \\
\hline \multirow{3}{*}{400} & 1 & 245 & 781 & 1067 \\
\cline { 2 - 5 } & 2 & 218 & 784 & 1071 \\
\cline { 2 - 5 } & 3 & 196 & 787 & 1075 \\
\hline \multirow{3}{*}{600} & 1 & 242 & 703 & 928 \\
\cline { 2 - 5 } & 2 & 215 & 708 & 934 \\
\cline { 2 - 6 } & 3 & 193 & 712 & 938 \\
\hline \multirow{2}{*}{800} & 1 & 239 & 648 & 826 \\
\cline { 2 - 5 } & 2 & 213 & 654 & 832 \\
\cline { 2 - 5 } & 3 & 192 & 660 & 838 \\
\hline
\end{tabular}

The entire wall is considered at the stagnation temperature when the timer reaches $5 \tau$ and for the second glass and the plate, the characteristic time observed is constant for each air velocity at a given insulation condition. However, this characteristic time decreases with increase in insulation because the walls absorb more heat energy ( $\alpha_{g 1} \alpha_{g 2} S H_{s}$ for the second glass and $\alpha_{g 1} \alpha_{g 2} \alpha_{p} S H_{s}$ for the plate). That is the reason for temperature elevation with insulation and corresponding characteristic time reduces.

In contrast, the first glass characteristic time depends on air velocity. Indeed, time drops with velocity because the temperature decreases when the velocity raises. The glass requires less energy as the velocity increases and in this condition the characteristic time is also weaker.

Analysis of solar cooker with storage

Charging and discharging analysis of box type solar cooker with storage has been carried out in this section.

It can be depicted from the figure 4 that the storage material used for storage of sensible heat is magnesia and it shows the variation of the temperature of the storage with respect to the different solar radiations and it shows that the temperature increases exponentially with respect to the time and it becomes stagnant after certain duration due to the reason that the temperature gradient inside the storage among the different layers is reduced which decreases the heat transfer. While considering the discharging process the variation of storage temperature during discharging process has been explained in figure 5 and it can be seen that the temperature decreases exponentially initially and becomes stagnant after certain duration and the reason behind this is the temperature 
gradient and stratification are less, however along the length variation is more at initial layer during charging and the same has been depicted during discharge process.

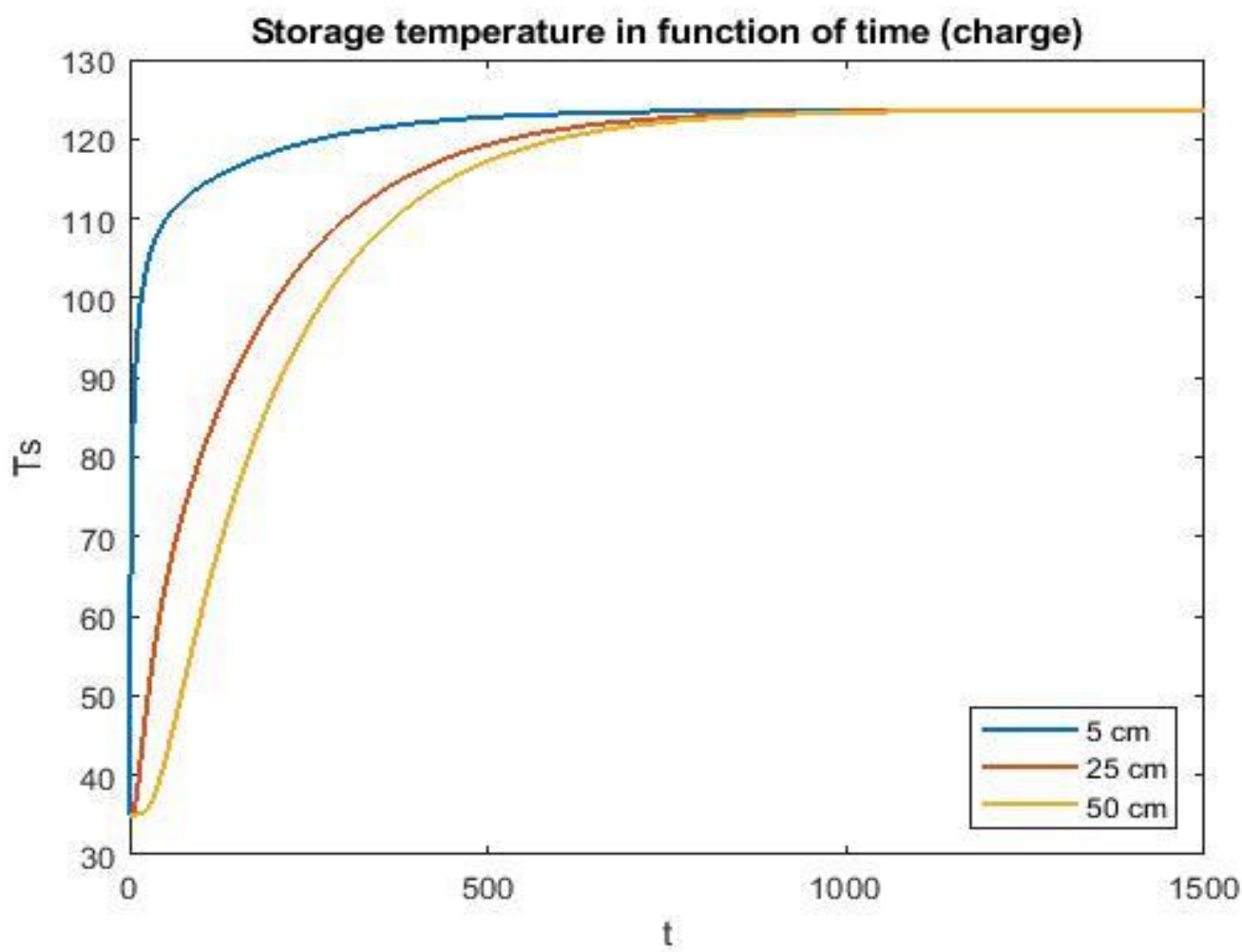

Fig. 4. Variation of storage temperature with time

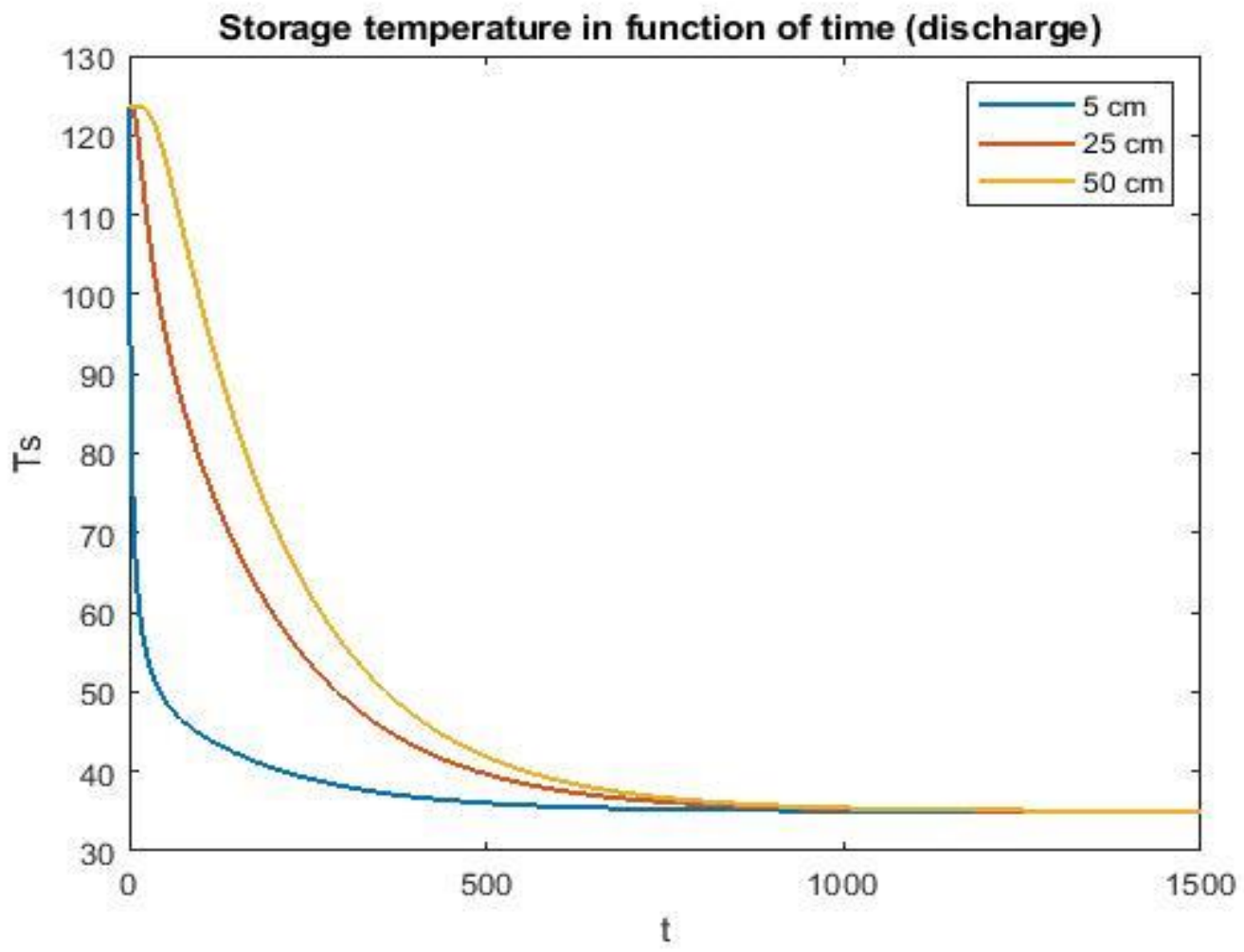

Fig. 5. Variation of storage temperature with time during discharging 
Charge and discharge analysis

For analysis purpose the storage system is divided in equal parts with a thickness of $L / N$. It is considered that the heat in the plate spreads by conduction and transfers its heat to the first layer of the storage material. Then, each layer dissipated its heat to the one at lower temperature until there is a stagnation plate temperature achieved by each layer. Each layer will take time to reach the stagnation temperature and the total charging time of the storage will be the sum of the time to reach the stagnation temperature by an individual layer. For calculating the total discharging time of the thermal storage system of solar cooker, the same approximation method is being used. The first layer will transfer its heat until the plate reaches the stagnation temperature, and there is no heat transfer because of same temperature.

For the charging phase, the total final time is considered when the temperature reaches $99 \%$ of the stagnation plate temperature. For the charging, the final time is considered when the temperature reaches $101 \%$ of the ambient temperature.

Table 3. Parametric analysis for different insolation conditions with storage in cooker

\begin{tabular}{|c|c|c|c|c|c|}
\hline$H_{S}\left(W / m^{2}\right)$ & $\mathrm{v}(\mathrm{m} / \mathrm{s})$ & $t_{c h}(\mathrm{~s})$ & $\mathrm{t}_{\mathrm{ch}}(\mathrm{h}: \mathrm{min})$ & $t_{\text {dis }}(s)$ & $t_{\text {dis }}(h: \min )$ \\
\hline \multirow[t]{3}{*}{400} & 1 & 12041 & $3: 20$ & 16193 & $4: 30$ \\
\hline & 2 & 12026 & $3: 20$ & 16155 & $4: 29$ \\
\hline & 3 & 12016 & $3: 20$ & 16121 & $4: 29$ \\
\hline \multirow[t]{3}{*}{600} & 1 & 12250 & $3: 24$ & 17145 & $4: 46$ \\
\hline & 2 & 12241 & $3: 24$ & 17107 & $4: 45$ \\
\hline & 3 & 12229 & $3: 24$ & 17082 & $4: 45$ \\
\hline \multirow[t]{3}{*}{800} & 1 & 12355 & $3: 26$ & 17791 & $4: 56$ \\
\hline & 2 & 12353 & $3: 26$ & 17753 & $4: 56$ \\
\hline & 3 & 12338 & $3: 26$ & 17724 & $4: 55$ \\
\hline
\end{tabular}

It can be observed cooker has a great power storage because the case may be almost 5 hours. Charging times is practically constant whereas discharging times raise with insulation. The following graphs represent the first figure of merits across charging and discharging time:

It can be observed from the above figures 6 and 7 that the first figure of merit so the loss heat coefficient has a big influence on the charging and discharging.

For the charging duration, storage needs more time to keep energy when heat losses are high initially due to high temperature difference. But during the discharge of the cooker storage the discharge time is more which is more beneficial because the temperature difference between the plate and the storage are not very high therefore heat losses are high during charging phase but low during discharging. 


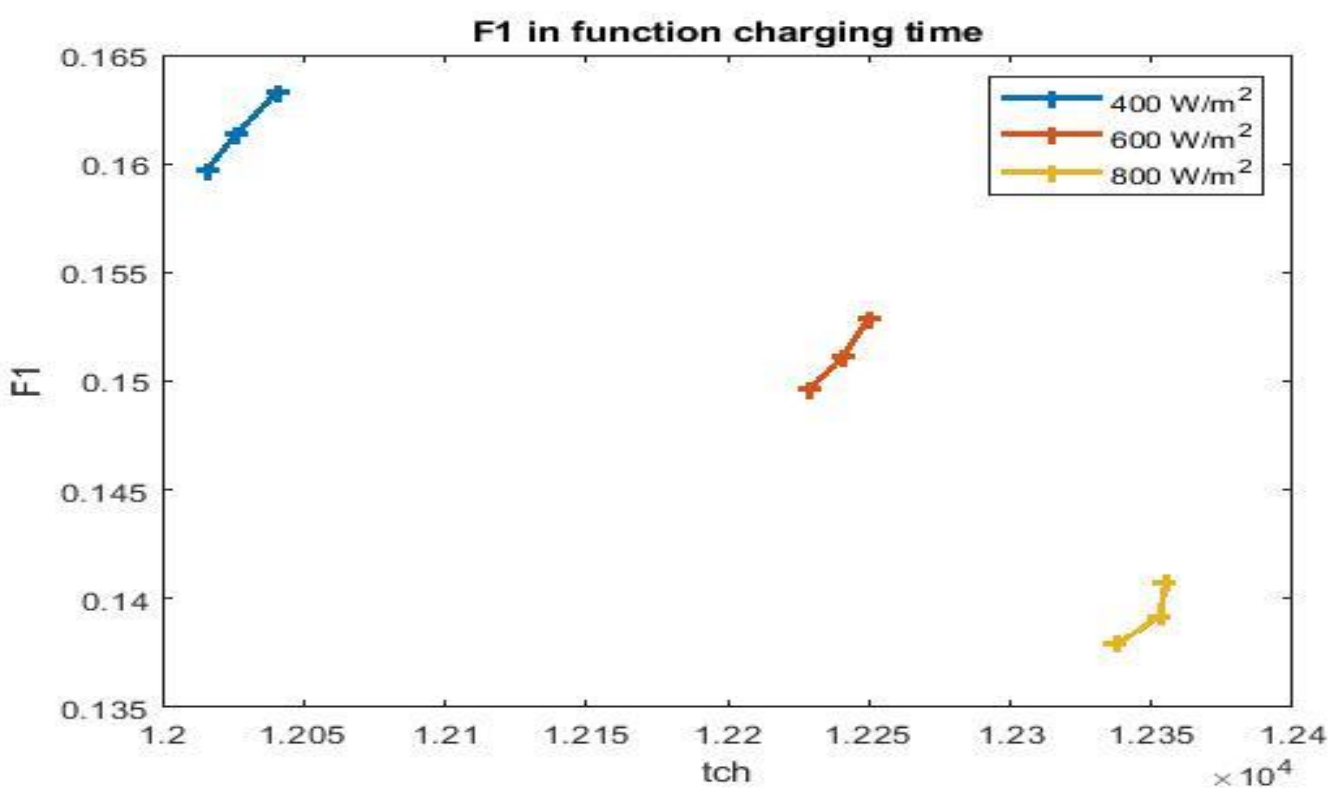

Fig. 6. Variation of first figure of merit with charging time

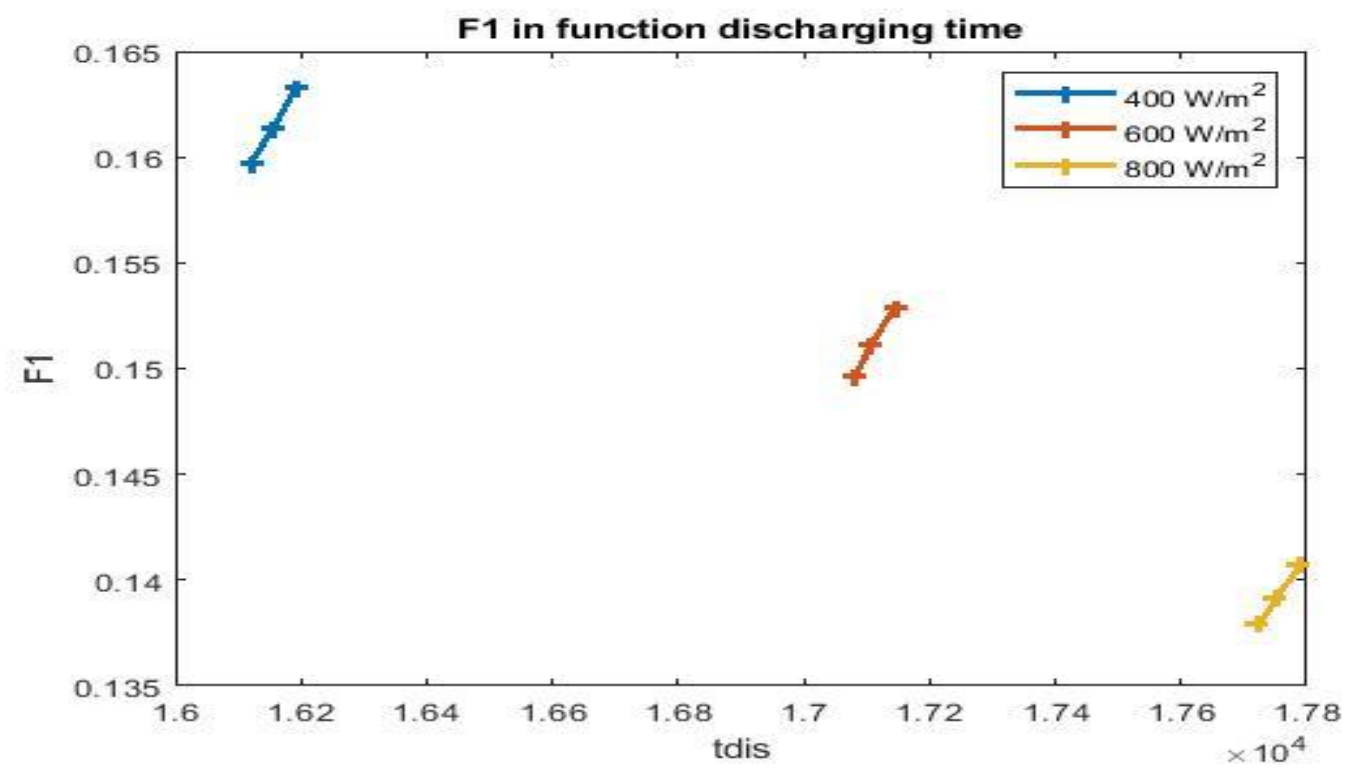

Fig. 7. Variation of first figure of merit during discharging

\section{Impact}

The present analysis of box type solar cookers is carried out to determine the thermal performance. The charging and discharging time characteristic of heat in the cooker is analysed in order to determine the time taken for each. Energy stored in the storage material will keep the cooker warm up to the time when food is consumed. The thermal performance of box type solar cookers is measured in terms of figures of merit according to BIS standards. The present novel idea of a box type solar cooker packed with the storage material is to store the thermal energy during charging time and discharge the heat during discharging, when there is no solar radiation. This cooker will keep the food warm for about 4-5 hours, thus saving fuel energy for heating the food again. There will be fuel saving and this will lead to the economic benefit of the people using this type of cooker. The novel cooker with storage design and fabricated will impact the economic condition in the rural area by saving money for cooking and reheating the food using fuel/LPG. This system will deliver an economic benefit by saving the fuel energy and have a deep impact on the environment by using a non-polluting source of energy. 


\section{Conclusion}

A mathematical model of a solar cooker is proposed to determine convection and radiation coefficients. These coefficients allowed us to identify the wall temperatures and the characteristic times of each wall. The calculation of the first figure of merit permitted to show the good performance of the cooker, selected for study with storage. Then, a storage system was added, and modelling allowed to bring the possibility to use solar cookers during cloudy or after sun hours. The first figure of merit has also an influence of charging and discharging time benefits in a case and harmful in another.

The F1 has a significant effect on charging and discharging time while effect of storage has been taken into consideration in box type solar cooker.as charging time is approximately 2-3 hours whereas the same heat takes a time of 4-5 hours for discharge, hence has a significant effect on performance of solar cooker the heat stored during charging can be used during night or cloudy days.

\section{Conflict of interest}

There are no conflicts to declare.

\section{Acknowledgments}

This research has not been supported by any external funding.

\section{References}

[1] A. Soria-Verdugo, Experimental analysis and simulation of the performance of a box-type solar cooker, Energy Sustain. Dev. 29 (2015) 65-71. https://doi.org/10.1016/j.esd.2015.09.006.

[2] Volunteers in Technical Assistance, Solar Cooker Construction Manual, Mt. Rainier, Md. VITA, Maryland, USA, 1967.

[3] S. Didierjean, Lecture notes in Heat transfer by conduction, in: 2018.

[4] J.A. Duffie, W.A. Beckman, Solar Engineering of Thermal Processes, 4th ed., John Wiley \& Sons, Inc., Hoboken, New Jersey, 2013.

[5] A.I. Fernandez, M. Martnez, M. Segarra, I. Martorell, L.F. Cabeza, Selection of materials with potential in sensible thermal energy storage, Sol. Energy Mater. Sol. Cells. 94 (2010) 1723-1729. https://doi.org/10.1016/j.solmat.2010.05.035.

[6] T.E. Bowman, J.H. Blatt, Solar Cookers, History, Design, Fabrication, Testing and Evaluation, Florida Institute of Technology, Florida, 1978.

[7] H.P. Garg, B. Bandyopadhyay, G. Dutta, Mathematical Modelling of the Performance of a Solar Cooker, Appl. Energy. 14 (1983) 233-234. https://doi.org/10.1016/0306-2619(83)90066-1.

[8] J.S. Vaishya, T.C. Tripathi, D. Singh, R.H. Bhawalkar, M.S. Hegde, A hot box solar cooker: Performance analysis and testing, Energy Convers. Manag. 25 (1985) 373-379. https://doi.org/10.1016/01968904(85)90057-3.

[9] A. Weldu, L. Zhao, S. Deng, N. Mulugeta, Y. Zhang, X. Nie, W. Xu, Performance evaluation on solar box cooker with reflector tracking at optimal angle under Bahir Dar climate, Sol. Energy. 180 (2019) 664677. https://doi.org/10.1016/j.solener.2019.01.071.

[10] F. Yettou, B. Azoui, A. Malek, A. Gama, N.L. Panwar, Solar cooker realizations in actual use: An overview, Renew. Sustain. Energy Rev. 37 (2014) 288-306. https://doi.org/10.1016/j.rser.2014.05.018.

[11] S. Geddam, G.K. Dinesh, T. Sivasankar, Determination of thermal performance of a box type solar cooker, Sol. Energy. 113 (2015) 324-331. https://doi.org/10.1016/j.solener.2015.01.014.

[12] M. Collares-Pereira, A. Cavaco, A. Tavares, Figures of merit and their relevance in the context of a standard testing and performance comparison methods for solar box - Cookers, Sol. Energy. 166 (2018) 21-27. https://doi.org/10.1016/j.solener.2018.03.040.

[13] S.C. Mullick, T.C. Kandpal, S. Kumar, Testing of box-type solar cooker: Second figure of merit F2 and its variation with load and number of pots, Sol. Energy. 57 (1996) 409-413. https://doi.org/10.1016/S0038092X(96)00116-8. 